\title{
Information technology competencies for entry-level human resource strategic partners
}

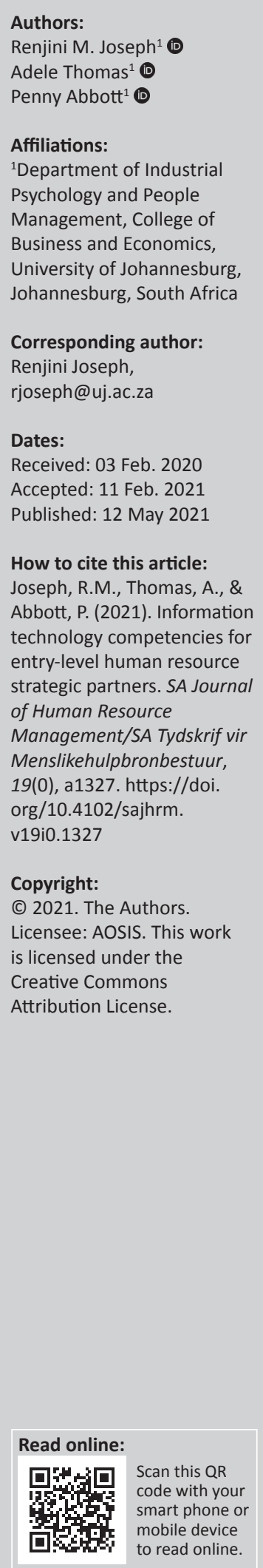

Orientation: Advances in information technology (IT) have prompted the transition of the human resource management (HRM) function from being administrative to strategic. Whilst it has been established that IT has an important role in such a transition, it is not clear to what extent the development of IT competencies would enable HRM professionals to be strategic.

Research purpose: The purpose of the article is to determine the IT competencies that will enable entry-level South African HRM professionals to be strategic partners to business.

Motivation for the study: The findings of this study will contribute to the effective use of HR technology, thereby mitigating risk and enriching the role of the HR function in local organisations. The use of technology within the HRM function can be enhanced leading to improved data-driven people decisions.

Research approach, design and method: A quantitative research design using a cross-sectional survey was employed. Data collected from $252 \mathrm{HR}$ professionals were analysed using exploratory factor analysis (EFA). Multiple regression was used to establish the relationship between the identified factors and strategic business partnering.

Main findings: The results produced a three-factor model consisting of: (1) technologising employee processes, (2) processing data expertly and (3) translating external trends. These factors explained $34 \%$ of the variance in strategic business partnering.

Practical implications: The results of this study have implications for organisations with HRM functions and for higher education institutions (HEIs) offering HRM qualifications. Organisations should utilise the identified competencies when hiring and developing entrylevel strategic HRM business partners. Higher education institutions should develop curriculum that would prepare graduates to be effective HRM professionals.

Contributions or value-add: This study adds to the limited research on IT competencies required of HRM professionals to contribute as strategic business partners.

Keywords: human resource business partners; exploratory factor analysis; human resource graduate; human resource management; human resource education.

\section{Introduction}

The human resource management (HRM) function has been evolving over the years and quite substantially during the last two decades, because of the rapid technological and related advances in the world of work (Marler \& Fisher, 2013). The HRM profession also continues to evolve to accommodate changes both external and internal to the organisation (Binuyo \& Brevis-Landsberg, 2014; Marler \& Fisher, 2013; Samkarpad, 2013).

Specifically, the use of human resource (HR) technology has altered how HRM professionals address their functions, through the reduction of transactional costs, the increase of capacity and flexibility of HR information and the improvement of the reach and richness of such information (Martin \& Reddington, 2010; Nam, 2019). These changes imply that the HR professional need to understand HR technology. However, HR professionals have traditionally selected HRM as a career because it emphasises 'people skills' (Heneman, 1999). Competencies required to utilise HR technology effectively may differ from such traditional competencies expected of an HR professional.

Several competency frameworks have been developed to identify the new competencies that are required of HRM professionals (Coetzer \& Sitlington, 2014; Nam, 2019; Suen \& Yang, 2013). However, these frameworks do not detail information technology (IT) competencies, especially 
in relation to HR professionals' ability to strategically partner with business (Poba-Nzaou, Uwizeyemungu, \& Stanate, 2016; Suen \& Yang, 2013). Additionally, existing competency frameworks imply that each HR professional must exhibit a large number of competencies independently, which may be an onerous expectation (Mamman \& Al Kulaiby, 2014; Ulrich, Kryscynski, Ulrich, Brockbank, \& Slade, 2016). Human resource professionals may play different roles within their organisation, depending on the organisational size, their seniority and other factors (Banerjee, Bandyopadhyay, \& Acharya, 2013). Thus, competencies of HRM professionals may vary according to seniority.

This study aims to identify IT competencies that will enable entry-level South African HR professionals to be strategic partners to business. In a study in South Africa, Joseph (2019) identified IT competencies that are expected of entry-level HR professionals through a Delphi process incorporating the views of 25 local experts.

This article extends the findings of the study to determine the importance of the various IT competencies required of entrylevel HRM professionals to be strategic business partners, which has also not been examined sufficiently in the literature. This study excludes competencies outside of the use of HR technology and information, which may be expected of such professionals because of the general evolution of HRM in organisations.

Theoretically, this study has roots in human capital theory, whereby people's learning and learning capacities compare to other resources utilised in obtaining organisational success (Nafukho, Hairston, \& Brooks, 2004).

Thus, human capital theory attempts to clarify how education and training can be a form of investment in HRs. From the same perspective, education is viewed as deliberate ventures to prepare the labour force and increase productivity of both individuals and organisations (Nafukho et al., 2004).

Thus, the identification of IT competencies will guide the development of HRM curricula in higher education institutions (HEIs), which, in turn, will lead to better equipped present and future workplace-ready for HRM professionals. By improving the utilisation of HR information, such professionals will also support organisations in South Africa by providing strategic solutions to business partners. Furthermore, the identification of IT competencies for entry-level HRM professionals will enable organisations to determine which skills sets professionals must bring to the organisation.

\section{Research objectives}

The objectives of this study are:

- to establish the factors associated with IT competencies that enable entry-level HRM professionals to be strategic partners to business
- to determine how the identified IT competencies required of entry-level HR professionals relate to strategic business partnering.

\section{Competencies and behavioural indicators}

Competencies have been described as the knowledge, skills and attributes an individual should have to perform a particular task (McClelland, 1973; McEvoy et al., 2005; Younger, Brockbank, \& Ulrich, 2012). Competencies are also described as broad concepts that incorporate demonstrable performance outputs and behavioural inputs, and are variously categorised as behavioural or technical in nature (Chartered Institute of Personnel and Development [CIPD], 2014). Spencer and Spencer (1993) describe competencies as underlying characteristics that have causal relationships to superior job or situational performance. For the purpose of this study, the description and categorisation offered by McClelland (1973) is used. Whilst McClelland describes competencies as knowledge, skills and attributes, it may not be possible to identify a particular competency as knowledge, skill or attribute exclusively. In order for someone to display competence in a particular area, a combination of knowledge, skills and attributes relevant to a particular area must be exhibited. In such instances, isolating only the knowledge, skill or attribute associated with that area may be challenging.

Competencies, or behavioural indicators that comprise competencies, can be written either formatively or reflectively. Reflective indicators enable an individual to reflect on whether a competency is indicated (Brinckmann, 2007), whilst formative indicators enable an individual to improve at a selected competency.

Formative competencies pinpoint what indicators people must possess to be considered competent (Brinckmann, 2007). In this study, competencies are described using formative behavioural indicators.

\section{Human resource technology}

Human resource technology encompasses the use of integrated software and hardware for automating various HR tasks in organisations (Hawking, Stein, \& Foster, 2004). Human resource information can be extracted and applied to make strategic HR decisions (Nagendra \& Deshpande, 2014). The use of technology reduces administrative load, allowing HR professionals to focus on their strategic role. Furthermore, improved HR information analysis heightens the strategic contribution that the HR function could make to organisational success (Kovach, Hughes, Fagan, \& Maggitti, 2002). The use of HR information systems (HRISs) is viewed as an opportunity for organisations to ensure that their HR function participates more in the operations of the organisation (Barrett \& Oborn, 2013; Sadiq, Khan, \& Ikhlaq, 2012; Stone \& Deadrick, 2015). Whilst some organisations use HRISs to reduce costs and to facilitate improved communication, others use such systems to re-orient HR operations which, in turn, improves the strategic contribution of the HR function (Sadiq et al., 2012; Zhang \& Wang, 2006). 
The use of HR technology can highlight areas of HR risk. Proper monitoring and analysis of HR information can prompt HR professionals to take actions to minimise negative risk and maximise positive risk (Farndale, Paauwe, \& Boselie, 2010). Contrarily, by not using HR information, HR professionals potentially expose themselves and their organisations to different forms of risk. Paul and Mitlacher (2008) argue that strategy-oriented HR risk systems can facilitate the transition of the HR function towards being more professional and strategic.

Amidst all the research related to the role of technology in the HR function and its ability to contribute strategically, the competencies of the HR professionals interacting with these HRISs are seldom discussed (Poba-Nzaou et al., 2016). Studies indicate that, in many organisations, HRISs are used in such a way that it supports the administrative role, rather than the strategic role played by the HR function (Barrett \& Oborn, 2013; Sadiq et al., 2012). Thus, the inability of HR functions to transition from administrative to strategic contributors may be because HR professionals may not have the competencies to work with HRISs or the data obtained through such systems (Ulrich, Younger, Brockbank, \& Ulrich, 2013).

\section{Strategic business partnering}

At a basic level, strategic HR business partners are expected to concentrate on business as opposed to focusing only on employees (Ulrich, 2013). According to Colbert (2004), strategic HRM originates from two foundational assertions. Firstly, the HRs of an organisation are of strategic importance to the organisation's success in formulating and implementing strategy. The second assertion is that organisational HRM practices contribute to the development of strategic capability within its HRs pools. Thus, strategic HRM is closely affiliated to the resource-based view of competitive advantage in the organisation's resource base (Colbert, 2004). Thus, organisations need to study and optimise HRM practices and the use of technology in doing so, in order to develop its strategic capability.

Human resource professionals are now expected to do more than they used to, because with the strategic orientation of the function, HR professionals are now looked to for organisational design and systems, as well as their change management expertise (Ramlall, 2006). However, typically, organisational management and employees view HRM as a support function and a cost centre, which primarily focuses on employees, as opposed to contributing to formulate and implement strategy (Kryscynski, Reeves, Stice-Lusvardi, Ulrich, \& Russell, 2018; Lawler \& Mohrman, 2003). Strategic HR business partners, however, should be able to identify talent, recognise critical positions and plan for development and succession (Hutcheson, 2004). This implies that although organisations would like to be strategic about managing their people, they may not be suitably prepared.

\section{Use of information technology in strategic human resource management}

A study conducted by Ankrah and Sokro (2012) in Ghana concluded that the use of HRIS in organisations leads to improved strategic decision-making. Using HRIS improves the quality of information, which enables fact-based decisionmaking in the HR function, which, in turn, leads to a greater commitment to employee development in organisations. Although the study established that the use of an HRIS leads to operational savings in terms of cost and time (Ankrah \& Sokro, 2012), the authors note that organisations must carefully consider HRIS planning, implementation and longevity, if they are to maximise their return on investment.

Haines and Lafleur (2008) note that HR functions are information intensive. There are studies that report on the positive impact IT and HR practices have had on firms' performance (Huselid, 2018). The transformation of the HR function has been credited to the availability of IT and its use in streamlining and improving the efficiency of core and administrative services. Furthermore, with enterprise resource planning, the HR function can improve its efficiency and become more involved, strategically speaking, in the organisation.

Contradicting the findings of the studies mentioned above, research by Quinn and Brockbank (2006) found that the effect of HR technology on business performance is not strategically significant. This implies that HR technology is not crucial, unless it can be linked to business performance. Quinn and Brockbank (2006) indicate that there may thus not be a need for complex technology, intricate service delivery and design models, or rigorous data analysis systems within HR functions.

The abovementioned contradictions also suggest that the utilisation of technology for strategic purposes may not depend on the technology itself, but possibly the competence of HR professionals in using the technology available to them. This view is strengthened by the fact that employees without HR qualifications are being employed in the HRM function (Bondarouk \& Ruël, 2013), although Heneman (1999) remarks that it is the combination of people and analytical competencies that makes for a value-adding HRM professional.

Organisations may have limited choice related to such appointments, as many HR qualifications do not develop these competencies. Such non-HR appointments damage the credibility of the profession, heightening calls to identify what competencies HRM professionals should have, and what technological competencies they need in particular.

\section{Information technology competencies}

The introduction of HR technology implies that HRM professionals have access to more detailed employment indicators, which should enable them to better forecast labour trends and hiring needs. This change in itself indicates a need to revisit HRM professionals' competencies (Schramm, 2006). Furthermore, understanding technology enables 
HRM professionals to speak the language of business, as technology is embedded in almost every aspect of business (Schramm, 2006). A sound grasp of technology will enable HRM professionals to collaborate, organise work, build teams and develop new knowledge and skills, which can help create organisational and human capital. Most importantly, HRM processes can be streamlined with the use of technology to free up resources to make a strategic contribution to the business (Schramm, 2006).

Johnson and King (2002) point out that it is critical to evaluate whether the educational qualifications developed for the profession to sufficiently prepare graduates with the required competencies, especially given the number of changes HRM has undergone. Managing HR technology systems is complex, and therefore, HRM professionals with strong IT competencies will be in demand for some time to come (Marler \& Parry, 2016). Leading companies expect entry-level HRM professionals to be strategic business partners who can align themselves with other business functions, in order for the organisation to achieve success (Johnson \& King, 2002). If technology causes fundamental changes to the HRM function, then these must also be reflected in HRM-related education (Hempel, 2004). These concerns were noted in the early 2000s and considering that HR education has not evolved to accommodate these considerations, the HR profession faces the risk of not transforming itself fast enough to adjust to the changes in the larger global economy.

By contrast, as reported by Johnson and King (2002), whilst traditional $\mathrm{HR}$ and industrial relations (IRs) competencies are incorporated into curricula, there is little intent to develop business-aligned competencies. If HRM students are not taught basic IT competencies at the university level, a great deal of time and resources will have to be invested to make those graduates effective in the workplace (Autor, 2015). Additionally, organisations may not be willing to invest in what they perceive to be a support function (Mondore, Douthitt, \& Carson, 2011). Addressing technology in professional education, and not just as an 'add-on' training course, will facilitate the development of an HR graduate who would expedite the transition of the role of the HR professional from administrative to more strategic (Lawler, Levenson, \& Boudreau, 2004).

Relatively few publications focus on the IT competencies HRM professionals require. Although a variety of competency frameworks have been developed to enable these professionals to become more strategic (Caldwell, 2008; Cohen, 2015; Lee \& Yu, 2013; Thite, Budhwar, \&Wilkinson, 2014; Younger et al., 2012), only a few appear to be pertinent to the area of IT competencies (Joseph, 2019; Poba-Nzaou et al., 2016; Schramm, 2006). Whilst all these competency frameworks suggest that IT competencies are necessary for HRM professionals to be strategic, only a few publications in this field describe what these actually entail.

Whilst the impact of IT on the HRM function and its services to the organisation is studied both conceptually and empirically, the literature on IT competencies has been predominantly conceptual (Hempel, 2004; Schramm, 2006). An empirical study in the area used competencies identified in the literature (both in the IT and HR fields), but the sample used in that instance was limited, consisting only of working students (Poba-Nzaou et al., 2016). The study also did not take into consideration the various levels of experience, which HRM professionals have.

Thus, this study aims to determine the IT competencies that will enable entry-level HRM professionals to be strategic partners to business, and the extent to which these IT competencies enable strategic partnering.

\section{Method \\ Research design, setting and respondents}

The study used a quantitative research approach and is cross-sectional in nature. A survey incorporating the competencies identified in the study by Joseph (2019) was pilot-tested and subsequently distributed to more than 2500 HRM professionals to determine the extent to which they thought that the identified competencies will enable entry-level HRM professionals to be strategic partners to business. The questionnaire included 27 IT competencies, incorporating 45 behavioural indicators (Joseph, 2019). The respondents needed to have at least a year of experience in the field of HRM to determine the importance of IT competencies and their relationship with strategic business partnering. Therefore, HR professionals with at least 1 year of experience, with varied educational backgrounds and from different sectors, were chosen as respondents.

Volunteer sampling was used, as the respondents were selfselected. Two forms of questionnaire design were used, namely a delivery-and-collection questionnaire and a web questionnaire. Out of the 339 responses that were collected, 252 were utilisable.

The target population of the study were HRM professionals. The sample consisted of $66 \%$ women and $34 \%$ men. A total of $43.7 \%$ of the respondents had postgraduate qualifications, whilst $54.3 \%$ had a degree or diploma and $2 \%$ had matric qualifications. A total of $86.1 \%$ of respondents have either completed or are currently pursuing an HR qualification. And $70.2 \%$ of the respondents had more than 8 years of experience, with an additional $16.3 \%$ having between 5 and 8 years of experience. A total of $5.6 \%$ of respondents had below 3 years of experience.

All results were reported with integrity and objectivity. Respondents were made aware of the purpose of the study. All respondents gave their consent before participating in the survey. Participation was voluntary and respondents could withdraw from the study at any time. Privacy was maintained by keeping all responses private and secure. All participants' information remained confidential. 


\section{Data analyses}

The statistical analysis methods included Cronbach's alpha coefficient, Bartlett's test of sphericity, the Kaiser-MeyerOlkin (KMO) measure of sampling adequacy, Catell's scree test, parallel analysis and exploratory factor analysis (EFA) using maximum likelihood and promax rotation. The Cronbach's alpha coefficient was measured to test reliability, associated with the accuracy and precision of a measuring instrument (Suhr \& Shay, 2009). Testing the reliability of the questionnaire used in this study also helped determine the relationships between the various items, which was the second purpose of testing the reliability. The Cronbach's alpha coefficient scores of all categories were in the acceptable range of 0.70-0.95 (Cohen, Manion, \& Morrison, 2013), which implies that the survey items were strongly correlated. Thus, the items were considered for further analysis and interpretation, as the internal consistency was high enough to be deemed reliable.

Further, the researcher used EFA to determine whether a factor, or several factors, could summarise the larger set of items, and to explore the interrelationships amongst the various items. Exploratory factor analysis is appropriate to explore the main dimensions that enable the generation of a theory or model from a relatively large set of latent constructs (Suhr, 2006). Tabachnick and Fidell (2007) suggest that the sample size must be greater than five times the number of items, if a sample is to be considered suitable for factor analysis. Considering that there were 36 items including demographic items, with a sample size of 252, more than seven times the number of items, the sample size was deemed suitable for factor analysis. The extraction technique used was maximum likelihood factoring (Pallant, 2016), which is considered the best choice when data are relatively normally distributed (Costello \& Osborne, 2005). Bartlett's test of sphericity and the KMO measure of sampling adequacy were considered to assess the factorability of the data. Bartlett's test should be statistically significant at $p<0.05$, and the KMO measure should have a value of 0.6 or above (Pallant, 2016; Tabachnick \& Fidell, 2007). The $p$ value for Bartlett's test was lower than 0.05. Furthermore, the KMO value was higher than 0.60 . Thus, EFA was considered appropriate for the next step in the analysis.

Following factor analysis, the researcher examined the variables that could be attributed to each factor and gave the factor a name or theme. Such labelling is considered subjective, theoretical and inductive in nature (Williams, Brown, \& Onsman, 2010). The factors identified during this phase explained most of the responses.

The results of the online survey and the development of the factors of the proposed IT competencies were based on the findings of the EFA. The data generated from the survey responses were sufficient, reliable and valid. Furthermore, the researcher used multiple regression to test the relationship between the identified IT competencies and strategic business partnering. The assumptions of linearity and 'no multicollinearity' were met.

\section{Ethical considerations}

The College of Business Economics Research Ethics Committee approved ethical clearance for this study on 04 May 2016 with the ethical clearance number: IPPM2017-168 (D).

\section{Results \\ Categorising the identified competencies}

The parallel analysis suggested three factors. Furthermore, based on the scree test (used to assist in decisions regarding the number of factors), three factors were retained for further investigation. The three factors identified had initial Eigenvalues exceeding 1. The initial factors explain $44.0 \%$, $7.6 \%$ and $5.3 \%$ of the variance, respectively, which is $57 \%$ of the variance in total. On inspecting the associated scree plot, a break was seen after the third factor. Therefore, using the scree test, three factors were retained for further investigation. Table 1 depicts the pattern matrix that indicates oblique rotation and the factor loadings of the various items. The communalities of all items are above 0.3 .

\section{Factor 1: Technologising employee processes}

In examining the items that grouped within the first factor and their relationships, the first factor was collectively named 'technologising employee processes' - as it captures the various behavioural indicators that group within this factor into a larger component. The highest item loaded at 0.917 and the lowest at 0.336 .

Thus, the factor showed a number of strong loadings and all items loaded strongly on factor 1 . None of the items were dropped, as none of them had low loadings. Moreover, the purpose of the EFA was not to remove items, but to categorise them. The factor entitled 'technologising employee processes' had a high Cronbach's alpha $(\alpha=0.954)$ and the mean interitem correlation was 0.509 , indicating that the factor has high internal consistency.

\section{Factor 2: Processing data expertly}

On analysing the relationships amongst the items that grouped within the second factor, the factor was labelled 'processing data expertly'. The name of this factor is a representation of the various behavioural indicators that cluster within this factor. The factor showed a number of strong loadings and all items loaded strongly on Factor 2. The highest item loaded at 0.815 and the lowest item loaded at 0.389 . Once again, none of the items were dropped. The factor entitled 'processing data expertly' has a high Cronbach's alpha $(\alpha=0.898)$ and the mean inter-item correlation was 0.406 , which imply that the factor has high internal consistency.

\section{Factor 3: Translating external trends}

Finally, three items clustered to form a third factor. The relationships amongst the items that group within this third 
TEP_1. Defines a problem, question or hypothesis based on the needs of stakeholders

TEP_2. Contributes to designing experiences for the end user (employee or manager)

TEP_3. Manages change associated with implementing HR technology

Explains and calculates HR metrics

TEP_4. Identifies relevant HR metrics by considering organisational context

TEP_5. Identifies existing HR transactions that can be integrated into new processes

TEP_6. Makes predictive inferences from data

TEP_7. Identifies the needs of the end user (employee or manager) through observation, engagement and empathising

TEP_8. Reacts to change with technological perspectives, tools and techniques, in order to make change seamless

TEP_9. Breaks down HR processes into specific transactions

TEP_10. Translates the capabilities of technological products to particular organisational or stakeholder situations

TEP_11. Connects human issues in the workplace to related data

Views the organisation and the HR function as a system and as part of a system

TEP_12. Applies data-mining outputs and big data insights to HR issues

TEP_13. Taps into information from other functions to benefit the HR function

TEP_14. Identifies the impact of HR decisions on employees

TEP_15. Effectively connects information from various systems

TEP_16. Modifies existing processes to collect accurate data

TEP_17. Evaluates whether various systems used for HR information have appropriate data security or access levels

TEP_18. Displays HR process ownership

PDE_1. Maintains data accuracy in a single system or multiple systems.

PDE_2. Organises data for ease of reading (sorting, splitting and filtering).

PDE_3. Displays proficiency in the use of spreadsheet and database programmes.

PDE_4. Continually maintains the quality of an information system.

PDE_5. Transfers data from one system to another for processing purposes.

PDE_6. Summarises different forms of data into meaningful information.

PDE_7. Focuses on HR processes to ensure that data obtained have integrity.

PDE_8. Maintains electronic records taking into consideration information governance.

PDE_9. Understands that data relevant to a particular context may not be used in another context.

PDE_10. Identifies gaps in processes if data quality obtained is poor.

PDE_11. Identifies risks that could arise if data are not protected.

PDE_12. Applies basic statistical methods to solve problems.

PDE_13. Identifies types of employee data needed to resolve a problem.

TET_1. Applies various forms of social media for two-way communication with potential employees, employees and managers

TET_2. Utilises various tools available through social media to achieve various tasks

TET_3. Is aware of new trends and products in technology that could impact HR

$\mathrm{HR}$, human resource.

factor were analysed to term this factor 'translating external trends'. The factor name aptly characterises the behavioural indicators that cluster within this factor. The loading pattern indicates the highest item loading at 0.935 and the lowest loading at 0.568 . All items loaded strongly on factor 3 . This analysis indicates that the three items may be collapsed into one factor. None of the items were dropped. The factor entitled 'translating external trends' has a high Cronbach's alpha $(\alpha=0.892)$ and the mean inter-item correlation was 0.732 .

Thus, the three factors obtained through the EFA were used to categorise the various identified IT competencies. Once the identified IT competencies were categorised, the relationship between IT competencies and strategic business partnering was investigated.

\section{Relationship between information technology competencies and strategic business partnering}

Multiple regression was used to determine the relationship between the identified IT competency themes and strategic business partnering. For multiple regression to be used, various assumptions need to be met, and therefore, these were first tested. Collinearity diagnostics was performed as part of the multiple regression procedure to identify any problems related to multicollinearity. The results are presented in Table 2 .

As the tolerance value was not less than 0.1 for any of the factors, the possibility of multicollinearity was rejected. Variation inflation factor (VIF) values below 5 also reject multicollinearity; thus, the assumption of multicollinearity was met in this model.

An inspection of the normal probability plot (P-P) of the regression standardised residual and the scatterplot also revealed no major deviations from normality.

One outlier was identified in the scatterplot. As the number of outliers was small, when compared to the sample, no action was deemed necessary. The Mahalanobis distances produced by the multiple regression programmes were also inspected 
TABLE 2: Extract from the coefficient table in multiple regression analysis.

\begin{tabular}{|c|c|c|c|c|c|c|c|}
\hline \multirow[t]{2}{*}{ Model } & \multicolumn{2}{|c|}{ Non-standard coefficients } & \multirow{2}{*}{$\frac{\text { Standard coefficients }}{\beta}$} & \multirow[t]{2}{*}{$t$} & \multirow[t]{2}{*}{ Sig. } & \multicolumn{2}{|c|}{ Collinearity statistics } \\
\hline & $\beta$ & Std. error & & & & Tolerance & VIF \\
\hline \multicolumn{8}{|l|}{1} \\
\hline (Constant) & 2.145 & 0.226 & - & 9.475 & 0.000 & - & - \\
\hline Technologising employee processes (factor 1 ) & 0.484 & 0.075 & 0.580 & 6.468 & 0.000 & 0.353 & 2.836 \\
\hline Processing data expertly (factor 2 ) & 0.097 & 0.080 & 0.095 & 1.222 & 0.223 & 0.469 & 2.132 \\
\hline Translating external trends (factor 3 ) & -0.066 & 0.045 & -0.103 & -1.463 & 0.145 & 0.574 & 1.741 \\
\hline
\end{tabular}

Note: Robust standard errors were also computed because of the slight heteroscedasticity in the residuals. There was not much difference in the standard errors and associated $t$-statistics. Therefore, these are not reported.

$\mathrm{VIF}$, variation inflation factor.

TABLE 3: Correlations between identified factors and strategic business partnering.

\begin{tabular}{|c|c|c|c|c|}
\hline Characteristics & $\begin{array}{l}\text { Strategic business } \\
\text { partnering }\end{array}$ & $\begin{array}{l}\text { Technologising employee } \\
\text { processes (factor 1) }\end{array}$ & $\begin{array}{l}\text { Processing data } \\
\text { expertly (factor } 2 \text { ) }\end{array}$ & $\begin{array}{l}\text { Translating external } \\
\text { trends (factor } 3 \text { ) }\end{array}$ \\
\hline \multicolumn{5}{|l|}{ Pearson's correlation } \\
\hline Strategic business partnering & 1.000 & - & - & - \\
\hline Processing data expertly (factor 2 ) & 0.467 & 0.729 & 1.000 & - \\
\hline Translating external trends (factor 3 ) & 0.321 & 0.652 & 0.485 & 1.000 \\
\hline \multicolumn{5}{|l|}{ Sig. (2-tailed) } \\
\hline Technologising employee processes & 0.000 & - & - & - \\
\hline Processing data expertly & 0.000 & 0.000 & - & - \\
\hline Translating external trends & 0.000 & 0.000 & 0.000 & - \\
\hline \multicolumn{5}{|l|}{$N$} \\
\hline Strategic business partnering & 252 & - & - & - \\
\hline Technologising employee processes & 240 & 240 & - & - \\
\hline Processing data expertly & 243 & 234 & 243 & - \\
\hline
\end{tabular}

Note: $p$ less than 0.001

to check for outliers. The critical value of the Mahalanobis distance for two independent variables was 13.82 (Tabachnick \& Fidell, 2007). On analysing the Mahalanobis distance of all the cases, only one case had a high value (14.055). Considering that there was only one outlier, it was decided not to remove the case for further analysis.

Furthermore, it was identified that no items had a Cook's distance of more than 1 . In fact, the highest Cook's distance was 0.128 , indicating that no single case had any undue influence on the results of the model as a whole. The correlations between the various factors are provided in Table 3.

All independent variables showed a correlation coefficient higher than 0.3 . Factor 1 and factor 2, namely technologising employee processes and processing data expertly, correlated substantially with strategic business partnering $(r=0.582$ and $r=0.467$, respectively). The analysis of variance (ANOVA) table, as shown in Table 4, indicates that the model reached statistical significance.

A multiple linear regression was calculated to predict strategic business partnering based on technologising employee processes (factor 1), processing data expertly (factor 2) and translating external trends (factor 3 ).

Expressed as a percentage, the three identified factors explained $34.0 \%$ of the variance in strategic business partnering, as indicated in Table 5.
TABLE 4: Analysis of variance table for the multiple regression analysis.

\begin{tabular}{lccccc}
\hline Model & Sum of squares & $d \boldsymbol{f}$ & Mean square & $\boldsymbol{F}$ & Sig. \\
\hline $\mathbf{1}$ & & & & & \\
Regression & 27.383 & 3 & 9.128 & 41.028 & 0.000 \\
Residual & 51.169 & 230 & 0.222 & - & - \\
\hline Total & $\mathbf{7 8 . 5 5 2}$ & $\mathbf{2 3 3}$ & - & - & - \\
\hline
\end{tabular}

TABLE 5: Model summary table for the multiple regression analysis.

\begin{tabular}{lcccc}
\hline Model & $\boldsymbol{R}$ & $\boldsymbol{R}^{2}$ & Adjusted $\boldsymbol{R}^{2}$ & Std. error of the estimate \\
\hline 1 & $0.590 \dagger$ & 0.349 & 0.340 & 0.47167
\end{tabular}

Significance is 0.000 .

To compare the extent to which each of the factors contributed to the prediction of strategic business partnering, the standardised beta values in Table 2 were used. The largest beta coefficient was associated with factor 1 , which implies that the factor makes a unique contribution towards explaining strategic business partnering, when the variance explained by the other factors in the model is controlled for. The beta values for factors 2 and 3 were much lower, indicating a contribution to strategic business partnering, although less than factor 1.

Table 2 also indicates that factor 1 made a statistically significant unique contribution to the equation. The statistically significant values of both the other factors were high, which can possibly be explained by the overlap amongst the independent variables.

To summarise, the results of the multiple regression analysis indicated that the three factors collectively explained 34\% of the variance in strategic business partnering. Additionally, 
all three factors correlated strongly with strategic business partnering. The first, technologising employee processes, was particularly significant.

\section{Discussion Outline of the results}

The survey was utilised to identify the combination of the IT competencies that would most closely relate with strategic business partnering. The first competency category, which requires entry-level HRM professionals to technologise employee processes, refers to them designing systems, running processes and using technology with the intention of providing strategic outputs to business. This particular factor features competencies related to business process and leveraging technology. Thus, understanding business processes and leveraging technology are deemed necessary for entry-level HRM professionals if they are to be strategic partners to business. The second competency category, processing data expertly, also links quite strongly with strategic partnering. Without data, there is no way of strategically partnering with business. Data are the instruments through which strategic partnerships can be strengthened. Even in this factor, there are some competencies that can be considered business process competencies. With reference to the third competency category, awareness and use of social media enable entry-level HRM professionals to adapt quickly to trends, making the information they provide relevant and effective. The combination of the three factors explains more than a third of the variance in strategic business partnering, which is considered to be significant.

\section{Factor 1: Technologising employee processes}

The first factor, entitled 'technologising employee processes', refers to the entry-level HRM professional being the intercessor or link between technology and the people processes in the organisation. The literature supports this finding, in that HRM professionals must be comfortable with HR technology from the onset (Hussain \& Prowse, 2004; Quinn \& Brockbank, 2006). Human resource IT is widely used and is important for the daily operations of HRM functions (Hussain \& Prowse, 2004). Whilst the use of IT in HR enables increased efficiency, effectiveness and integration, Hussain and Prowse (2004) note that early use of HR IT is almost always for operational purposes. The findings of this study imply that the operational management of HR IT systems may be something entry-level HRM professionals should be doing.

Pretorius (2009) states that how the HRM function is performed and managed in an organisation must be radically changed before technology can empower that function. Pretorius (2009) further suggests that the competitive advantage that good HR technology provides is the information it produces, which then affects the quality of decisions.

There are contrasting views about the importance of technology for the HRM function. Selmer and Chiu (2004), in identifying competencies, only mention technology under the 'innovation' role that the HRM executive may perform, but they do not refer to HRM technology in their discussion of that role. In most competency frameworks, HR processes and technology are some of the last competencies to be included, being least correlated with HR success. However, this study suggests that unless HR technological competencies are valued appropriately, some higher order competencies (such as strategic business partnering, change and innovation) may not be of much value within the HRM function. So, whilst these competencies may not be important for HR executives, they are vital for entry-level HRM professionals. This assertion is supported by the fact that this factor makes the strongest unique contribution to strategic business partnering competencies for entry-level HRM professionals.

\section{Factor 2: Processing data expertly}

The second identified factor was named 'processing data expertly'. Most of the competencies clustered within this factor refer to data processing, analysis and management. The literature backs the finding that the competencies identified in this category are important for HRM professionals (Farndale et al., 2010). For Farndale et al. (2010), the HRM functions in multinational corporations focus on their administrative processes, strongly emphasising data and metrics.

Several studies support the need for analytical abilities in HRM professionals. There is, however, also an argument that data analytics is not an HRM professional's job (Isson \& Harriott, 2016), but it has been identified that a basic understanding of data processing will be helpful (Kryscynski et al., 2018). Some argue that data analytics competencies are not necessarily IT competencies, as data are products of IT. Nevertheless, in this study, it was identified that factors 1 and 2 were highly correlated. Thus, data-processing competencies are considered IT competencies for the purposes of this study.

For data to be accurate, there must be a clear link between people, processes and technology. In other words, having this competency category is not sufficient - it is not standalone. In fact, in many instances, organisations have poor data. Human resource management professionals do not know how to fix data or how to process them, even if the processes are fine. This mutual dependence explains the high correlation between these categories.

The findings of this study support the idea that entry-level HRM professionals must not only be comfortable with data, but must also be experts at processing, and not necessarily analysing, data. The findings further imply that the analysis may happen at a senior level, but entry-level HRM professionals must understand the basics, so that they can collect and process data in order for analysis at senior levels to be effective. 


\section{Factor 3: Translating external trends}

The third factor identified refers to external trends. Kryscynski et al. (2018) agree that HR professionals who identify important trends create more value for the business. Appreciating external trends enables HRM professionals to understand how such trends can assist the organisation in meeting its needs. For example, when flexible working grew as a concept, an HRM professional who understood the trend would have prepared policies, processes and systems to accommodate this, giving employees an opportunity to do flexi work. The quicker the adaptation, the more strategic the contribution the HRM professional can make to the organisation. Also, this factor included social media competencies and an awareness of trends and new products in technology. In this study, it was identified that this factor makes only a limited contribution to strategic business partnering. Boudreau (2014) and Poba-Nzaou et al. (2016) interpret the identified competencies in their respective studies as not sufficient for strategic business partnering. The competencies that cluster within this factor are thus recognised to not be strategic in isolation, but are beneficial to strategic business partnering, if exhibited by entry-level HRM professionals.

Furthermore, these findings are in line with the point made by Boudreau (2014) that HRM functions are not at the forefront of addressing organisational dilemmas or external trends. An HRM professional who can interpret external trends can strategically advise on the impact that recent phenomena such as globalisation and the fourth industrial revolution can have on the employees and potential employees of an organisation. The competencies that HRM professionals possess in relation to linking employee processes to technology and data processing will also enable them to make decisions related to various trends, and to report back on the success of any associated initiatives.

Ignoring these competencies and being unable to scope out external trends can pose a threat to the organisation as a whole and to the HRM function in particular, preventing the entity from being able to respond to such trends (Phelps, 2010). Thus, interpreting external trends is a necessary IT competency for any entry-level HRM professional.

The results of this study suggest that the identified IT competencies correlate significantly with strategic business partnering. A limited number of studies have linked IT competencies and strategic business partnering. Uti (2016) discusses that being a technology proponent is significantly but weakly correlated with the strategic partnering role of HRM professionals. Being a technology proponent had one of the weaker correlations when compared to other competency areas - the Pearson's correlation coefficient value was only 0.304 . Notably, most other studies found that the use of IT in HRM can increase its strategic contribution (Barrett \& Oborn, 2013; Bondarouk \& Ruël, 2013; Martin \& Reddington, 2010), but few studies have linked IT competencies with strategic business partnering (Uti, 2016).
Uti's (2016) findings, in association with the findings of this study, can be interpreted in several ways. One perspective is that being a technology proponent is considered important for entry-level HRM professionals.

When considering the other competencies expected of senior HRM professionals (being a strategic positioner, a change champion and an HR innovator), the competencies associated with a technology proponent may become less significant. Entry-level HRM professionals can, however, exhibit these competencies, thus making their contributions strategic and enabling them to play an important and necessary role in both the HRM function and the organisation. Hussain and Prowse (2004) also suggest that each set of HRM professionals uses HR IT differently. Thus, whilst senior HRM professionals may support the use of technology for organisational processes, entry-level HRM professionals should focus on technologising employee processes and ensuring that the data obtained through various IT systems are useable. Secondly, there may be a specific need for IT competencies amongst HRM professionals specifically in South African industries.

Thus, the findings of this study suggest that South African entry-level HRM professionals have to focus on the technical aspects of business processes and data analysis, for several reasons: firstly, it affords them an opportunity to understand the business and to grapple with the intricacies of people processes. Secondly, it positions them as contributors to the overall HR strategy of the organisation. Also, through the effective use of technology, they can arrive at a detailed understanding of the administrative processes within the organisation, and of how the organisation functions. Another reason for focusing on IT competencies and associated expertise is that becoming proficient should make them more effective as senior HRM professionals later on in their careers.

\section{Practical implications}

Organisations may use the identified IT competencies to ensure that they hire the right entry-level HRM professional, especially if they would like their HRM function to contribute strategically to the organisation.

Human resource management professionals with analytical abilities show higher overall individual performance, creating greater value for both the external and internal stakeholders of the organisation (Kryscynski et al., 2018). In some instances, hiring the right individual may not be sufficient. Organisations might consider incorporating the identified competencies into their performance management processes. Human resource technology organisations must also encourage the development of HR analytical skills at entry level. Many organisations choose to purchase basic HR technology, as their HRM function may not have the capability to use advanced versions. Thus, by developing the identified competencies in entry-level HRM professionals, both HR technology organisations and their clients can benefit. 
Further, it is suggested that the identified IT competencies be developed at the graduate level. The findings of this study indicate that HRM graduates do not need a complex or deep understanding of technology. It seems to be more important that entry-level HRM colleagues must be exposed to the use of technology in various HR processes, and to the management of the resulting data. They do not need to know highly sophisticated data-analysis techniques either, but should rather be exposed to more fundamental concepts pertaining to the processing of data, such that data can be used for rigorous decision making. Furthermore, they must have a solid understanding of the HR functional processes and how IT can be incorporated into existing processes.

Higher education institutions in South Africa must expose HRM students to at least an HRIS or e-HRM application during their qualification. Although this may be performed by introducing a stand-alone module in the curriculum, it is advisable that the e-HRM application be integrated into existing modules (Jones \& Hoell, 2005). By appreciating the use of data for making decisions at university level, HRM graduates will be well prepared to manage IT applications in the organisations in which they work. Furthermore, it is suggested that HR-simulated environments be introduced at tertiary institutions, so that pre-graduates can become comfortable utilising technology.

The development of the identified IT competencies alone will by no means be sufficient to ensure that HRM practitioners are capable of serving as strategic partners to business. As this study identified, HRM graduates must also possess several non-IT competencies. For example, Abbott (2011) emphasises the need for such graduates to have an understanding of ethics, and of the socioeconomic context in which the country functions.

\section{Limitations and recommendations for future research}

The current study did not take into consideration organisational factors such as the size, nature of the business and organisational culture, which fell outside of the scope of this undertaking. An investigation into the relationship between the identified IT competencies and the various organisational factors will be useful for determining whether IT competencies vary, depending on organisational factors such as those mentioned earlier.

This study identified those IT competencies that will enable entry-level HRM professionals to be strategic business partners. As HR technology can enable strategic partnering within the HRM function at all levels, it is recommended that the IT competencies required of mid-level and senior HRM professionals be studied in detail.

The study implies that competency categories may be interrelated. In this instance, business process and data analysis competencies were found to be highly correlated. This has implications for the way HRM work is distributed amongst various professionals, and the way HR technology is trained. Thus, it is recommended that the correlation amongst various competency categories in diverse competency frameworks be studied further. Such investigations can help to determine which competencies are complementary in nature.

The identified IT competencies can be utilised to develop curricula, as discussed previously. It would be of value to determine the role of the curriculum in delivering HRM graduates who can become strategic business partners. Furthermore, as suggested, various instructional strategies can be employed to develop the IT competencies identified here. A range of theoretical and practical activities and related outcomes can be utilised. It is important that such activities be evaluated from an educational perspective. In addition, the effectiveness of such strategies in developing entry-level HR strategic partners is an area for formal research and investigation.

The use of technology in HRM qualifications is another area that must be closely scrutinised. Using technology at different levels of complexity may develop diverse competencies in HRM graduates. It is recommended that the effects and outcomes of such use of technology be studied comprehensively. The assessment of the identified competencies is another area that might deliver interesting findings.

\section{Conclusion}

The first objective of this study was to group the identified IT competencies into specific categories. Following the EFA, the competencies clustered within three factors: technologising employee processes, processing data expertly and translating external trends. Thus, the broader IT competency groups were identified. The evidence from this study suggests that entry-level HRM professionals are expected to focus on internal HR processes, as well as dayto-day operational activities. As the results show, they can contribute to strategic business partnering to a moderate extent. In other words, by focusing on their functional and operational roles, they will be able to contribute as strategic business partners.

The second objective of this study was to determine how IT competencies required of entry-level HR professionals relate to strategic business partnering. The relationships between the identified IT competencies and strategic business partnering were identified through the multiple regression analyses. It was found that the identified IT competencies explained $34 \%$ of the variance in strategic business partnering - a considerable proportion. Thus, the study showed that the identified IT competencies explained a significant amount of variance in strategic business partnering, which means that the identified IT competencies are necessary for entry-level HRM professionals who wish to contribute by serving as strategic business partners. 
Before attempting to use people data to contribute strategically to an organisation, the HRM professionals working within this function must be sure about the quality, consistency, accuracy and integrity of that data. Without confidence in the collected data, making an effective strategic contribution may be difficult. The entry-level HRM professional may be crucial in ensuring that the data obtained can be utilised strategically. The competencies identified here indicate that if junior HRM professionals focus on technologising HR business processes and are capable of processing data proficiently, with an awareness of how to translate external technological trends, they can contribute to strategic business partnering to a large extent.

Higher education institutions, corporate organisations and professional bodies have a role to play in ensuring that an effective entry-level HRM professional is developed and supported. If this is performed, data-driven and strategic HRM can aid the function in addressing the future challenges facing the world of work.

Industrial revolutions not only influence the way business operates, but also the operations of organisational functions, work psychology and organisational culture. This study signals that a new intellect is required of the HRM professional, if businesses seek to be equipped for the fourth industrial revolution. With a process-orientated perspective and an analytical outlook, and without disregarding its foundation of employee advocacy, the HRM function can evolve to facilitate how organisations navigate the fourth industrial revolution.

\section{Acknowledgements}

The results discussed in this article are part of a larger study performed to fulfil the requirements of a doctoral qualification. R.M.J. was the doctoral candidate and A.T. and P.A. were her study guides. A special word of gratitude to Prof. Brandon Morgan is conveyed for his assistance with the data analyses.

\section{Competing interests}

The authors declare that they have no financial or personal relationship(s) that may have inappropriately influenced them in writing this article.

\section{Authors' contributions}

R.M.J. designed the study under the supervision of A.T. and P.A., R.M.J. conducted the research and was the main writer of the manuscript. A.T. and P.A. contributed to the analyses of results and writing of the manuscript.

\section{Funding information}

This research received no specific grant from any funding agency in the public, commercial or not-for-profit sectors.

\section{Data availability}

Data sharing is not applicable to this article as no new data were created or analysed in this study.

\section{Disclaimer}

The views and opinions expressed in this article are those of the authors and do not necessarily reflect the official policy or position of any affiliated agency of the authors.

\section{References}

Abbott, P. (2011). Human resources management in the South African socio-economic context. Johannesburg: University of Johannesburg.

Ankrah, E., \& Sokro, E. (2012). Human resource information system as a strategic tool in human resource management. Problems of Management in the 21st Century, 5, 6-15.

Autor, D.H. (2015). Why are there still so many jobs? The history and future of workplace automation. Journal of Economic Perspectives, 29(3), 3-30. https://doi. org/10.1257/jep.29.3.3

Banerjee, A., Bandyopadhyay, T., \& Acharya, P. (2013). Data analytics: Hyped up aspirations or true potential? Vikalpa, 38(4), 1-11. https://doi. org/10.1177/0256090920130401

Barrett, M., \& Oborn, E. (2013). Envisioning E-HRM and strategic HR: Taking seriously identity, innovative practice, and service. Journal of Strategic Information Systems, 22(3), 252-256. https://doi.org/10.1016/j.jsis.2013.07.002

Binuyo, A.O., \& Brevis-Landsberg, T. (2014). Does information and communication technologies contribute to organization performance? Evidence from Nigerian technologies contribute to organization performance? Evidence from Nigerian Retrieved from http://0-search.ebscohost.com.ujlink.uj.ac.za/login.aspx?direct=t

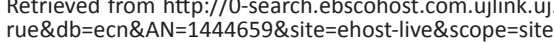

Bondarouk, T., \& Ruël, H. (2013). The strategic value of e-HRM: Results from an exploratory study in a governmental organization. The International Journal of Human Resource Management, 24(2), 391-414. https://doi.org/10.1080/095851 Human Resource
92.2012 .675142

Boudreau, J.W. (2014). Will HR's grasp match its reach? An estimable profession grown complacent and outpaced. Organizational Dynamics, 43(3), 189-197. https://doi. org/10.1016/j.orgdyn.2014.08.005

Brinckmann, J. (2007). Competence of top management teams and success of new technology-based firms. Frankfurt: Die Deutsche Nationalbibliothek. Retrieved from https://books.google.co.za/books?id=wlzYUCqnZbMC\&pg=PA173\&lpg= PA173\&dq=reflective+and+formative+indicators+competency\&source $=b \mid \& 0$

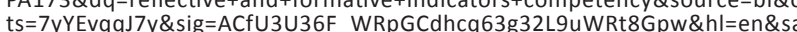
=X\&ved=2ahUKEwiEnuP8pZ hAhXCThUIHVseCrgQ6AEwBHoECAgQAQ\#v=one page\&

Caldwell, R. (2008). HR business partner competency models: Re-contextualising effectiveness. Human Resource Management Journal, 18(3), 275-294. https:// doi.org/10.1111/j.1748-8583.2008.00071.x

Chartered Institute of Personnel and Development (CIPD). (2014). Competence and competency frameworks - Factsheets - CIPD. Retrieved from http://www.cipd. co.uk/hr-resources/factsheets/competence-competency-frameworks.aspx

Coetzer, A., \& Sitlington, H. (2014). What knowledge, skills and attitudes should strategic HRM students acquire? A Delphi study. Asia Pacific Journal of Human Resources, 52(2), 155-172. https://doi.org/10.1111/1744-7941.12008

Cohen, D.J. (2015). HR past, present and future: A call for consistent practices and a focus on competencies. Human Resource Management Review, 25(2), 205-215. https://doi.org/10.1016/j.hrmr.2015.01.006

Cohen, L., Manion, L., \& Morrison, K. (2013). Validity and reliability. Research Methods in Education.

Colbert, B.A. (2004). The complex resource-based view: Implications for theory and practice in strategic human resource management. Academy of Management Review, 29(3), 341-358. https://doi.org/10.5465/AMR.2004.13670987

Costello, A.B., \& Osborne, J.W. (2005). Best practices in exploratory factor analysis: Four recommendations for getting the most from your analysis. Practical Assessment, Research \& Evaluation, 10(7), 1-9.

Farndale, E., Paauwe, J., \& Boselie, P. (2010). An exploratory study of governance in the intra-firm human resources supply chain. Human Resource Management, 49(5), 849-868. https://doi.org/10.1002/hrm.20387

Haines, III, V.Y., \& Lafleur, G. (2008). Information technology usage and human resource roles and effectiveness. Human Resource Management, 47(3), 525-540. https://doi.org/10.1002/hrm.20230

Hawking, P., Stein, A., \& Foster, S. (2004). e-HR and employee self service : A case study of a Victorian public sector organisation. Journal of Issues in Informing Science and Information Technology, 1, 1019-1026. https://doi. org/10.28945/2757

Hempel, P.S. (2004). Preparing the HR profession for technology and information work. Human Resource Management: Published in Cooperation with the School of Business Administration, The University of Michigan and in alliance with the Society of Human Resources Management, 43(2-3), 163-177. https://doi. org/10.1002/hrm.20013 
Heneman, R.L. (1999). Emphasizing analytical skills in HR graduate education: The Ohio State University MLHR program. Human Resource Management, 38(2), 131-134.

Huselid, M.A. (2018). The science and practice of workforce analytics: Introduction to the HRM special issue. Human Resource Management, 57(3), 679-684. https:// doi.org/10.1002/hrm.21916

Hussain, Z., \& Prowse, P. (2004). Human resource information systems (HRIS) as means of fulfilling job roles more professionally for human resource (HR) managers (No. 04/07). Bradford: University School of Management. https://doi. managers (No. 04/07).

Hutcheson, J. (2004). From black sheep to aspiring business partner: HR's turnaround at Delaware Investments. Journal of Organizational Excellence, 23(3), 33-43. https://doi.org/10.1002/npr.20014

Isson, J.P., \& Harriott, J.S. (2016). People analytics in the era of big data. Hoboken, NJ: Wiley

Johnson, C.D., \& King, J. (2002). Are we properly training future HR/IR practitioners? A review of the curricula. Human Resource Management Review, 12(4), 539-554. https://doi.org/10.1016/S1053-4822(02)00076-1

Jones, W.J., \& Hoell, R.C. (2005). Human resource information system courses: An examination of instructional methods. Journal of Information Systems Education, 16(3), 321-328.

Joseph, R.M. (2019). An information technology competency framework for entry level human resource strategic partners [Unpublished doctoral thesis]. University of Johannesburg.

Kovach, K.A.K., Hughes, A.A.A., Fagan, P., \& Maggitti, P.G. (2002). Administrative and strategic advantages of HRIS. Employment Relations Today, 29(2), 43-48. https:// doi.org/10.1002/ert.10039

Kryscynski, D., Reeves, C., Stice-Lusvardi, R., Ulrich, M., \& Russell, G. (2018). Analytical abilities and the performance of HR professionals. Human Resource Management 57(3), 715-738. https://doi.org/10.1002/hrm.21854

Lawler, III, E.E., Levenson, A., \& Boudreau, J.W. (2004). HR metrics and analytics: Use and impact. Human Resource Planning, 27(4), 27-36.

Lawler, III, E.E., \& Mohrman, S.A. (2003). HR as a strategic partner: What does it take to make it happen? Human Resource Planning, 26(3), 15-29. Retrieved from http://search.ebscohost.com/login.aspx?direct=true\&db=bth\&AN=10964093\& site=eds-live

Lee, E., \& Yu, K.S. (2013). How are global HR competency models evolving for the future? Retrieved from http://digitalcommons.ilr.cornell.edu/student/17/

Mamman, A., \& Al Kulaiby, K.Z. (2014). Is Ulrich's model useful in understanding HR practitioners' roles in non-western developing countries? An exploratory investigation across private and public sector organizations in the Sultanate Kingdom of Oman. International Journal of Human Resource Management 25(20), 2811-2836. https://doi.org/10.1080/09585192.2014.914053

Marler, J.H., \& Fisher, S.L. (2013). An evidence-based review of e-HRM and strategic human resource management. Human Resource Management Review, 23(1), 18-36. https://doi.org/10.1016/j.hrmr.2012.06.002

Marler, J.H., \& Parry, E. (2016). Human resource management, strategic involvement and e-HRM technology. The International Journal of Human Resource Management, 27(19), 2233-2253. https://doi.org/10.1080/09585192.2015. 1091980

Martin, G., \& Reddington, M. (2010). Theorising the links between e-HR and strategic HRM: A model, case illustration and reflections. The International Journal of Human Resource Management, 21(10), 1553-1574. https://doi.org/10.1080/095 85192.2010.500483

McClelland, D. (1973). Testing for competence rather than for 'intelligence'. American Psychologist, 28(1), 1-14. https://doi.org/10.1037/h0034092

McEvoy, G.M., Hayton, J.C., Warnick, A.P., Mumford, T.V., Hanks, S.H., \& Blahna, M.J. (2005). A competency-based model for developing human resource professionals. Journal of Management Education, 29(3), 383-402. https://doi.org/10.1177/ 1052562904267538

Mondore, S., Douthitt, S., \& Carson, M. (2011). Maximizing the impact and effectiveness of HR analytics to drive business outcomes. People \& Strategy, 34(2), 20-27. Retrieved from http://search.ebscohost.com/login.aspx?direct=tru e\&db=buh\&AN=63165744\&lang=de\&site=ehost-live

Nafukho, F.M., Hairston, N., \& Brooks, K. (2004). Human capital theory: Implications for human resource development. Human Resource Development International, 7(4), 545-551. https://doi.org/10.1080/1367886042000299843

Nagendra, A., \& Deshpande, M. (2014). Human Resource Information Systems (HRIS) in HR planning and development in mid to large sized organizations. Procedia Social and Behavioral Sciences, 133, 61-67. https://doi.org/10.1016/j.sbspro. 2014.04.169
Nam, T. (2019). Technology usage, expected job sustainability, and perceived job insecurity. Technological Forecasting and Social Change, 138(July 2018), 155-165. https://doi.org/10.1016/j.techfore.2018.08.017

Pallant, J. (2016). SPSS survival manual. A step by step buide to data analysis using IBM SPSS (6th edn.). New York, NY: Open University Press.

Paul, C., \& Mitlacher, L. (2008). Expanding risk management systems: Human resources and German banks. Strategic Change, 17(1/2), 21-33. https://doi.org/ $10.1002 / \mathrm{jsc} .813$

Phelps, R. (2010). Managing people in a changing world. Human Resource Management Key trends in human capital - a global perspective - 2010. PWC Saratoga Report, 1-43.

Poba-Nzaou, P., Uwizeyemungu, S., \& Stanate, A.N. (2016). Empirically derived IT competencies profiles for human resource managers: A working HR student's perspective. Journal of Higher Education Theory and Practice, 16(2), 11-30.

Pretorius, O. (2009). HR technology, creating more noise or the flywheel for transformation? In Global HR summit, 1-21.

Quinn, R.W., \& Brockbank, W. (2006). The development of strategic human resource professionals at BAE Systems. Human Resource Management, 45(3), 477-494. https://doi.org/10.1002/hrm.20120

Ramlall, S.J. (2006). Identifying and understanding HR competencies and their relationship to organizational practices. Applied H.R.M. Research, 11(1), 27-38. https://doi.org/PsychologicalScience

Sadiq, U., Khan, A.F., \& Ikhlaq, K. (2012). The impact of information systems on the performance of Human Resources department. Journal of Business Studies Quarterly, 3(4), 77-91.

Samkarpad, S. (2013). Status of Human Resource Information Systems (HRIS) in universities and affiliated colleges in Hyderabad. The IUP Journal of Organizationa Behaviour, 12(2), 20-42. Retrieved from http://ssrn.com/abstract $=2278048$

Schramm, J. (2006). HR technology competencies: New roles for HR professionals. 2006 SHRM Research Quarterly, 1-11.

Selmer, J., \& Chiu, R. (2004). Required human resources competencies in the future: A framework for developing HR executives in Hong Kong. Journal of World Business, 39(4), 324-336. https://doi.org/10.1016/j.jwb.2004.08.001

Spencer, L.M., \& Spencer, S.M. (1993). Competence at work: Models for superior performance. New York, NY: Wiley.

Stone, D.L., \& Deadrick, D.L. (2015). Challenges and opportunities affecting the future of human resource management. Human Resource Management Review, 25(2), 139-145. https://doi.org/10.1016/j.hrmr.2015.01.003

Suen, H.-Y., \& Yang, J.-M. (2013). HR professionalism in the computing environment: Predicting job performance within different HR roles. International Management Review, 9(1), 19-32.

Suhr, D. (2006). Exploratory or confirmatory factor analysis? Statistics and data analysis, 200(31). https://doi.org/10.1002/da.20406

Suhr, D., \& Shay, M. (2009). Guidelines for reliability, confirmatory and exploratory factor analysis. In conference proceedings of the Westerns Users of SAS Software, $1-15$.

Tabachnick, B.G., \& Fidell, L.S. (2007). Using multivariate statistics (7th edn.). Boston, MA: Pearson.

Thite, M., Budhwar, P., \& Wilkinson, A. (2014). Global HR roles and factors influencing their development: Evidence from emerging Indian IT services multinationals. Human Resource Management, 53(6), 921-946. https://doi.org/10.1002/hrm.21621

Ulrich, D. (2013). Human resource champions: The next agenda for adding value and delivering results. Boston, MA: Harvard Business Press.

Ulrich, D., Younger, J., Brockbank, W., \& Ulrich, M. (2013). The state of the HR profession. Human Resource Management, 52(3), 457-471. https://doi.org/ 10.1002/hrm.21536

Ulrich, M., Kryscynski, D., Ulrich, D., Brockbank, W., \& Slade, J. (2016). 2016 HR competency model. In Human resource competency conference (pp. 1-83). May 2016. Michigan.

Uti, C.A. (2016). The mediating effect of strategic partner role in the relationship between human resource competencies and organizational performance in the Nigerian banking sector. Journal of Marketing and Management, 7(2), 77-94.

Williams, B., Brown, T., \& Onsman, A. (2010). Exploratory factor analysis : A five-step guide for novices. Australasian Journal of Paramadicine, 8(3), 1-13. https://doi. org/10.33151/ajp.8.3.93

Younger, J., Brockbank, W., \& Ulrich, M. (2012). HR from the outside in: Six competencies for the future of human resources. New York: McGraw Hill Professional

Zhang, L., \& Wang, H. (2006). Intelligent information processing in human resource management: An implementation case in China. Expert Systems, 23(5), 356-369. https://doi.org/10.1111/j.1468-0394.2006.00416.x 